\title{
CMM e Comprometimento: Um estudo de caso na implantação do nível 2
}

\author{
Alba Scheible ${ }^{1}$, Antônio Virgílio Bastos ${ }^{2}$ \\ Universidade Federal da Bahia, UFBA \\ ascheibledunitech.com.br, virgiliodufba.br
}

\begin{abstract}
This paper analyzed organization and goal commitments and their relationship with functional and demographic variables in a software process improvement environment. The goal focused was "reaching maturity level 2 of the CMM model". Commitment patterns were determined in order to provide a better understanding of the human dimension in this kind of organizational change. Regression analysis identified that 33,2\% of organizational commitment was predicted by goal commitment in the sample studied.
\end{abstract}

Resumo. Este trabalho analisou os comprometimentos com foco na organização e no objetivo "atingir nível de maturidade nível 2 do modelo CMM”, bem como suas relações com variáveis funcionais e demográficas, em um ambiente de produção de software. Padrões de comprometimento foram delineados buscando colaborar para a compreensão da dimensão humana dos processos de melhoria do processo de software. Foi conduzida análise de regressão, que identificou o comprometimento com o objetivo como preditor do comprometimento organizacional na razão de 33,2\% na amostra estudada.

\section{Introdução}

O processo de desenvolvimento de software é um conjunto de ações requeridas para transformar as necessidades dos usuários em uma solução de software de maneira eficaz (HUMPHREY,1989). Estas ações estão inter-relacionadas com os aspectos pessoais dos indivíduos que as executam, como motivações e competências. Desta forma, pode-se compreender o processo de software como um conjunto complexo sob o ponto de vista social, com diferentes níveis: o indivíduo, as equipes ou grupos, os projetos e as organizações como um todo. Lyytinen (1988) apud Arbaoui (1999) define este processo social como "pluralista, ambíguo e inclinado a gerar conflitos". DeMarco (1999) sustenta que os maiores problemas para o sucesso dos projetos de software não são de ordem técnica, mas de natureza sociológica. Assim, fatores-chave para a melhoria nos ambientes de desenvolvimento de software estão não só nas suas dimensões técnica e metodológica, mas principalmente na dimensão humana.

Apesar das fundações das atividades que ocorrem neste tipo de ambiente serem calcadas na matemática formal, muitos pesquisadores vêm explorando as questões humanas que nelas ocorrem, principalmente porque elas possuem um papel primordial na adaptação ao dinamismo tecnológico próprio do setor, que torna este ambiente palco de mudanças constantes (ABRAHAMSSON, 2002). Efetuar mudanças nas organizações implica em transformar comprometimentos. Para tal, é necessário escolher uma âncora, um ponto de apoio. Seja um novo processo, novos valores, investimento em novos 


\section{Simpósio Brasileiro de Qualidade de Software}

recursos ou uma nova estratégia. Desta forma, a organização re-alinha suas ações em torno deste novo cenário, criando uma nova trajetória (SULL,2003). Neste contexto, encaixam-se novos modelos de qualidade para o processo de software como o Capability Maturity Model (CMM), que é bastante utilizado no mundo e vem sendo implantado de forma crescente em empresas brasileiras (MCT, 2005).

Este trabalho teve como objetivo analisar os comprometimentos com foco na organização e no objetivo atingir nível de maturidade nível 2 do modelo CMM, bem como suas relações com variáveis funcionais e demográficas, em um ambiente de desenvolvimento de software, e assim contribuir para o conhecimento dos fenômenos humanos que ocorrem neste contexto.

O campo do software é muito novo. Certamente muitas mudanças e otimizações virão no sentido de tornar o processo de sua produção mais efetiva. Humphrey (1989), idealizador do CMM, afirma que os principais problemas no processo de desenvolvimento de software são: requisitos mal definidos, mudanças sem controle, tempo insuficiente para testes, treinamento inadequado e padrões não gerenciados, e que todos estes se relacionam com o fenômeno do comprometimento. Os compromissos assumidos em termos de prazos, custos e qualidade não deixam de ser cumpridos por causa de técnicas ou ferramentas de tecnologia de ponta, mas devido à falta de comprometimento com eles. Ou seja, a base da gerência do processo de software é o comprometimento, o empenho das pessoas, inclusive da alta gerência, o que referenda Kinnula apud Abrahamsson (2002), afirmando que o fator humano constitui-se no elemento mais importante em atividades como a engenharia de software.

Salancik (1977) adiciona que certos tipos de comportamento podem contribuir para uma melhor produtividade, pois agir é comprometer-se. Comprometimentos moldam a identidade das empresas - definindo seus pontos fortes e fracos, configurando sua direção, estabelecendo oportunidades e limitações, e dando foco e motivando os empregados. Eles definem as estruturas estratégicas, recursos, processos, relacionamentos e valores, através de ações como: investimentos, desinvestimentos, promessas públicas, contratos, disseminação de informações, políticas de pessoal, etc. Portanto, comprometimentos devem ser tratados cuidadosamente.

As consequiências dos comprometimentos de longo prazo, como a implantação do CMM, não podem ser todas antecipadas. Portanto, antes de qualquer decisão, devese avaliar se o curso de ação a ser tomado. Comprometimentos precisam ser constantemente reforçados. Eles constroem eficiência, ajudam a manter o foco, atraem empregados e clientes. No entanto, também contribuem para enrijecer as ações das organizações, que engajam em cursos de ação dificilmente alterados, caso não sejam planejados para serem dinâmicos. Quando ocorrem mudanças inesperadas e ocorre pressão para cumprir os compromissos, estes devem ser reavaliados ao invés de persistir nas linhas de ação originais. Comprometimento, portanto, refere-se a qualquer ação tomada no presente que prende uma organização a um curso de ação futuro (SULL,2003).

Diversas tentativas foram feitas de conceituar e definir comprometimento. Vários autores de definições de comprometimento ressaltam suas diferenças em relação à motivação e outras atitudes, sugerindo que comprometimento influencia comportamento independente de outros motivos e atitudes, e que pode levar à 


\section{Simpósio Brasileiro de Qualidade de Software}

persistência em um modo de agir, mesmo diante de motivos e atitudes conflitantes (BECKER; 1960; BROWN,1996; KIESLER, 1971; MEYER e HERSCOVITCH, 2001; MOWDAY, 1998; MOWDAY et AL., 1982; SALANCIK, 1977; WIENER, 1982;). Devido à diversidade de interpretações e modelos, que resulta na falta de uma definição consensual e conseqüente fragmentação do construto, Meyer e Allen (2001) propuseram um modelo geral, que representou uma tentativa de integrá-las.

Este modelo atesta a existência de uma "essência nuclear" do construto, servindo como guia para a pesquisa do comprometimento, tendo sido utilizado neste estudo. É importante ressaltar que esta dificuldade de conceituação aparece a partir do termo "comprometimento" em si, que possui múltiplos significados associados ao seu uso na linguagem cotidiana e variações entre a língua inglesa e a portuguesa por possuírem raízes distintas - commit e comprommittere (BASTOS, 2000). Abrahamsson (2002) propõe a seguinte definição integrativa:

"Comprometimento é um estado de conexão que define a relação entre um ator (um
indivíduo, grupo ou uma organização) e uma entidade (foco). Esta relação pode ter
diferentes formas (afetiva, instrumental, normativa - base), que compartilha aspectos
comuns (durabilidade, força, foco, termos) com todas as formas de comprometimento"
(p. 43 ).

A literatura sobre comprometimento organizacional tem dado ênfase aos aspectos relacionados aos níveis individuais de comprometimento com diversos focos. A pesquisa sobre comprometimento voltada para sistemas de informação, no entanto, reconhece a existência de múltiplos níveis de comprometimento. Newman e Sabherwal (1996) identificaram o projeto, grupos sociais, chefia e a organização não só como focos, mas também como níveis. Ou seja, a organização, além de ser um foco de comprometimento, também pode agir no processo, demonstrando comprometimento com um projeto, por exemplo, através dos recursos que disponibiliza para ele.

O conceito do comprometimento com a organização surgiu de estudos que exploravam as relações entre empregado e organização. A razão para estes estudos era a crença que empregados comprometidos teriam maior potencial para um melhor desempenho, absenteísmo e rotatividade reduzida (MOWDAY, 1998). As definições de comprometimento, em geral, referem-se ao fato que comprometimento é uma força que estabiliza e direciona o comportamento. No entanto, quanto mais específicas a um determinado foco (por exemplo, organização), estas definições tornam-se mais abrangentes, envolvendo detalhes que dizem respeito à natureza ou origem da força que direciona o comportamento (MEYER e HERSCOVITCH, 2001).

A pesquisa do comprometimento com a organização tem se dividido em duas escolas de pensamento: atitudinal e comportamental (REICHERS, 1985). Comprometimento atitudinal advém, principalmente, do trabalho de Mowday et al. (1982) e de Porter e Buchanan. Já o comprometimento comportamental tem suas origens nos trabalhos de Becker (1960), Kiesler (1971) e Salancik (1977) (ABRAHAMSSON, 2003). Mowday (1982) explica a diferença entre as duas linhas de abordagem afirmando que: comprometimento atitudinal focaliza o processo através do qual as pessoas pensam sobre sua relação com a organização. Ou seja, o comprometimento com a organização se desenvolve a partir de experiências vividas no trabalho, percepções e características pessoais, que levam a sentimentos positivos em relação à organização. Já o comprometimento comportamental está relacionado com o 


\section{Simpósio Brasileiro de Qualidade de Software}

processo através do qual as pessoas se ligam a uma organização e como lidam com isso. Desta forma, os indivíduos se comprometem como resultado de terem se engajado em comportamentos de difícil reversibilidade, tendendo a repeti-los.

Salancik (1977) afirma que "agir é comprometer-se", refletindo sobre a dificuldade dos indivíduos em contradizer posições assumidas anteriormente. Meyer e Allen (1991) afirmam ser os dois tipos de comprometimento são processos complementares para a formação do vínculo comprometimento-comportamento. No entanto, o enfoque que dominou a literatura do comprometimento organizacional foi o afetivo, fundamentado no trabalho de Mowday, Porter e Steers (1982). Estes trabalhos eram calcados em uma perspectiva atitudinal, apesar de reconhecerem a existência de uma corrente comportamental (Medeiros, 2003).

Comprometimento com um objetivo é a determinação para atingi-lo, sendo um construto crítico para a compreensão da relação entre objetivos e desempenho ou resultados (KLEIN et AL., 2001). Ele vem sendo identificado como uma condição essencial, já que um objetivo não pode ter efeitos motivacionais sem que haja comprometimento (LOCKE e LATHAM, 1984). Estes autores afirmam que para obter comprometimento com um objetivo é necessário: a) explicar o objetivo a fim de que ele seja percebido como algo de valor e justo; b) prover suporte às pessoas que vão agir em prol do objetivo; (c) incentivar a participação de todos; (d) prover treinamento; (e) adequar processos seletivos; (f) distribuir incentivos e prêmios.

Existem duas correntes relacionas à pesquisa de comprometimento no processo de software: uma estuda os efeitos danosos do comprometimento quando ocorrem problemas nos projetos e outra que estuda os efeitos positivos do comprometimento (Sabherwal e Elam, 1995). Ambas utilizam como base os trabalhos de Kiesler (1971), Becker (1960) e Salancik (1977), que representam a linha comportamental da pesquisa sobre comprometimento. Comumente retratado como um fenômeno estático, comprometimento teve seu caráter dinâmico explorado nos estudos de Abrahamsson (2002), que mostrou a importância das redes de comprometimento para o sucesso de projetos de melhoria do processo de software. Conner e Patterson (1982) representaram o processo de construir comprometimento com foco em mudanças como um modelo causal, o que pode ser transportado para a implantação do CMM em uma organização, que se caracteriza como uma mudança não só operacional, mas também cultural.

O modelo causal apresentado por estes autores (Figura 1) representa o suporte à mudança ao longo do tempo, provendo um mapa de como construir comprometimento com mudanças organizacionais, permitindo aos gerentes planejar e preparar melhor as transições, o que maximiza suas chances de sucesso. Divide-se em 3 fases: (1) Preparação, (2) Aceitação e (3) Comprometimento; e possui 8 estágios para serem atravessados por indivíduos ou organizações a fim de que atinjam um estágio de comprometimento. O propósito da fase de preparação é sensibilizar para a mudança que irá ocorrer. $\mathrm{Na}$ fase de aceitação, ações são tomadas para viabilizar a execução da mudança, sendo onde os sinais de resistência à mudança são detectados. A institucionalização ocorre quando a mudança é internalizada (ABRAHAMSSON, 2002). Não se pode esperar atingir um senso absolutamente comum em relação a uma mudança como a implantação de um novo modelo de processo, como o CMM. No entanto, ela está longe de ser um processo solitário, individual e isolado. É por meio da possibilidade se situar no contexto organizacional e de compartilhar com os outros que 


\section{Simpósio Brasileiro de Qualidade de Software}

o sentido se realiza, e ao se realizar, possibilita aos indivíduos sua constituição como participantes da mudança (SILVA e VERGARA, 2003).

Figura 1 - Evolução do Comprometimento em Projetos de Melhoria (Abrahamsson, 2002)

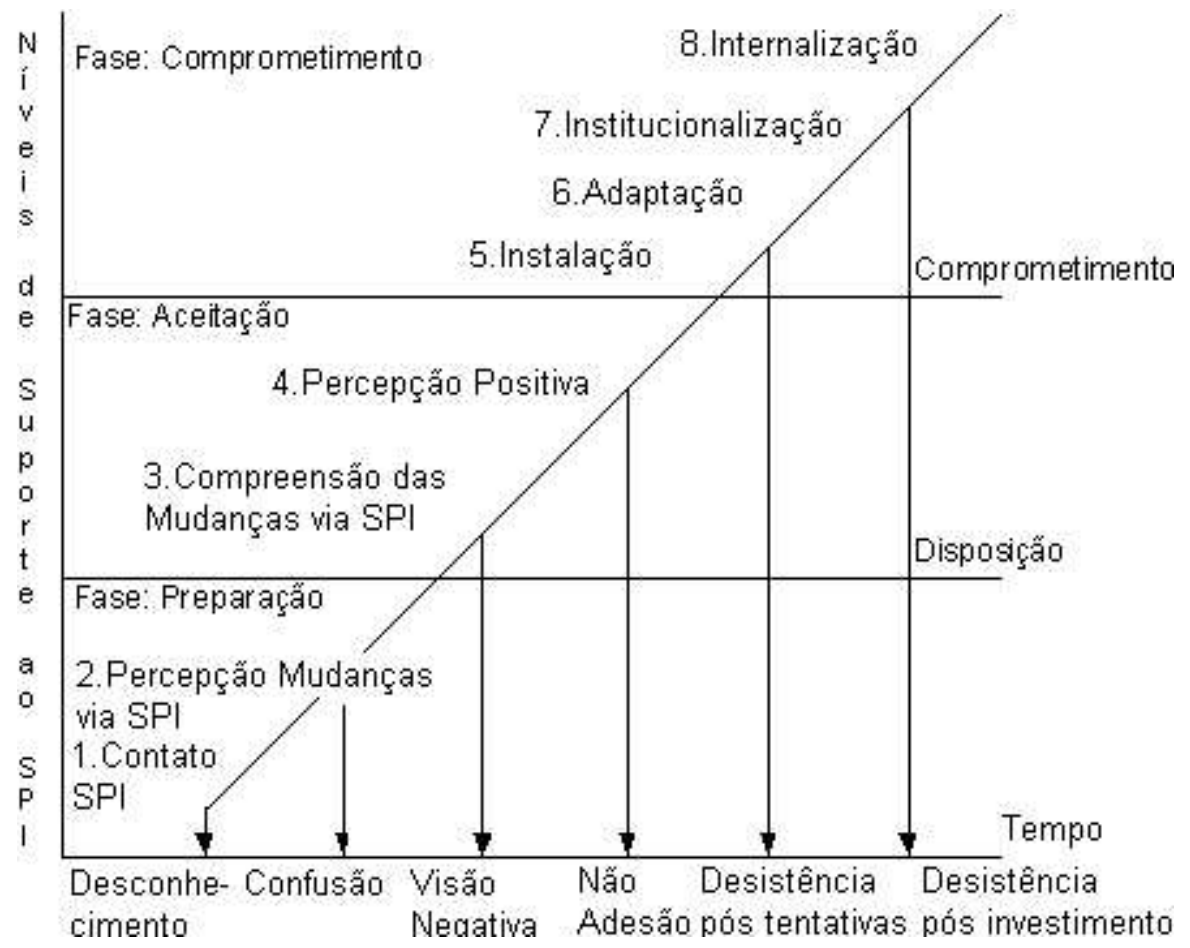

\section{Metodologia}

O universo alvo foi a fábrica de software de uma empresa profissional de serviços de tecnologia da informação, com sede na cidade de Salvador, Bahia. Trabalhou-se com uma amostra de cerca de $93 \%$ dos funcionários desta unidade, que se dispuseram a responder o questionário disponibilizado por correio eletrônico, perfazendo 110 participantes.

Para a coleta de dados, que aconteceu em dezembro de 2004, utilizou-se medidas com propriedades psicométricas validadas, como a escala HWK, desenvolvida em 1987 por Hollenbeck e Klein, e que teve sua dimensionalidade validada em 1989, constituindo-se no instrumento mais usado para aferir comprometimento com objetivo. Em 2001, Klein et Al. conduziram meta análise onde recomendam a continuidade de sua utilização em pesquisas, bem como a redução da quantidade de itens originais, que resultou em uma escala "mais pura e mais eficiente".

Para mensurar o comprometimento com a organização, foi utilizada a Escala de Comprometimento Afetivo de Meyer et AL.(1993), já utilizada no Brasil por Medeiros (2003) e Scheible (2004). Esta escala foi desenvolvida como parte de um instrumento, composto por dezoito indicadores, sendo seis para cada dimensão conceituada por eles: afetiva, normativa e instrumental. Somente foi utilizada a dimensão afetiva porque, segundo Benkhoff (1997), é a que apresenta melhores resultados. A utilização desta escala é recomendada por esta autora, bem como por Morrow (1993), que afirma que os dados de confiabilidade dela são "impressionantes". A confiabilidade destes instrumentos na presente pesquisa obteve os seguintes resultados: $\operatorname{HWK}(\alpha=0,5730)$ e 


\section{Simpósio Brasileiro de Qualidade de Software}

ACS $(\alpha=0,7435)$. É importante ressaltar que o foco organização refere-se à unidade onde foi conduzida a pesquisa (Fábrica de Software) e não a empresa a qual ela pertence. Antes da análise dos dados, utilizando o SPSS, foram eliminados os dados espúrios.

Os dados foram analisados utilizando médias e correlações. As médias referentes às variáveis demográficas foram calculadas, buscando estabelecer o perfil dos respondentes. As variáveis analisadas foram divididas em 3 categorias: demográficas, funcionais, e relativas ao comprometimento. Foram estabelecidos quatro padrões de combinação do comprometimento com a organização e atingir o nível 2 do CMM. Análises de variância foram utilizadas para testar as diferenças quanto às variáveis. Para estabelecer as correlações, foi utilizado o Coeficiente de Pearson. Os padrões de comprometimento com a organização e com o objetivo foram estabelecidos utilizando o procedimento quick cluster, a exemplo de Bastos (1994, 2000).

Bastos e Costa (2000) defendem que o estudo simultâneo do comprometimento do trabalhador frente a focos distintos mostra um avanço importante em relação à tradição dominante de estudos isolados de cada comprometimento. Bastos (1994) identificou quatro padrões combinando comprometimento com a organização e carreira/profissão, apresentando a seguinte caracterização: duplo compromisso, duplo descompromisso, unilateral com a organização, e unilateral com a carreira/profissão, permitindo, assim, traçar padrões que entrelaçam os comprometimentos em relação à carreira/profissão e à organização.

Foram examinados aspectos pessoais e ocupacionais que diferenciam os sujeitos que são caracterizados pelos padrões encontrados, concluindo que ambos podem afetar fortemente a diferenciação dos grupos, podendo favorecer ou não que os vínculos com a organização e a profissão sejam congruentes ou conflitantes. Neste trabalho, substituiuse o foco carreira pelo foco com o objetivo, ampliando o trabalho de Bastos (1994).

O nível de escolaridade dos respondentes é alto, com 37,8\% com formação universitária completa, sendo que $11,8 \%$ possuem títulos de pós-graduação. Considerando, aqueles que estão fazendo curso universitário, este número eleva-se para $98,3 \%$. Foi obtida correlação positiva e muito significativa, entre nível de escolaridade e renda individual $(0,652)$, demonstrando a importância deste fator no tipo de atividade tecnológica executado na organização alvo. Outras correlações, encontradas na amostra, com escolaridade foram: faixa etária $(0,545)$, número de dependentes $(0,264)$ e nível de renda familiar $(0,292)$. Vale ressaltar a correlação positiva com nível hierárquico, na ordem de 0,601 , demonstrando que a escolaridade é valorizada na organização.

A renda individual da amostra pode ser estratificada em 3 patamares: até 4 salários mínimos $(\mathrm{R} \$ 1.040,00)$, até 8 salários mínimos $(\mathrm{R} \$ 2.080,00)$ e acima de 8 salários mínimos, com os respectivos percentuais: 63,6\%, 23,6\%, e 12,8\%. Existe regime de trabalho de 6 horas para quem está cursando a universidade, o que lhes reduz a renda. A renda individual correlaciona-se fortemente, na ordem de 0,743 , com a faixa etária na amostra. Outras correlações obtidas foram: escolaridade $(0,545)$, conforme acima citado, número de dependentes $(0,367)$, nível de renda familiar $(0,333)$ e faixa etária $(0,652)$. Estes números denotam que a experiência é valorizada na organização alvo, pois as pessoas com faixa etária mais elevada possuem renda individual mais alta, de uma maneira geral. Foi encontrada correlação positiva com o nível hierárquico 


\section{Simpósio Brasileiro de Qualidade de Software}

$(0,730)$, indicando que os níveis hierárquicos mais altos recebem remunerações mais altas. No nível de renda familiar, observa-se maior estratificação da amostra.

No tocante à faixa etária, 73,6\% da amostra tem até 25 anos. Expandindo-se para 30 anos este limite, atinge-se 90,8\% da amostra, caracterizando-a como formada por indivíduos bastante jovens. As correlações foram encontradas, além das citadas anteriormente, com número de dependentes $(0,375)$ e renda familiar $(0,203)$. Fink (1992) é um dos estudos que aponta correlações positivas entre faixa etária e comprometimento com a organização. Em relação a sexo, 82,5\% são do sexo masculino, demonstrando o seu domínio em ambientes tecnológicos. Em pesquisa recente (Scheible, 2004), este percentual foi $66 \%$ para a empresa estudada como um todo. A distribuição da amostra por estado civil revela que $82,7 \%$ são solteiros, $14,5 \%$ são casados e $2,8 \%$ possuem outros estados civis. Consoante estes dados, a distribuição por dependentes aponta que $78,18 \%$ não possuem dependentes.

A distribuição em relação à ocupação revela que $60 \%$ são programadores e analistas de sistemas, $19 \%$ são líderes de equipe de desenvolvimento, $10 \%$ exercem funções de apoio, como Controle da Qualidade, Testes, e 11\% ocupam posições gerenciais, sendo coordenadores de projetos e a gerência propriamente dita. Este resultado é coerente com as características da organização alvo, que é uma empresa de prestação de serviços em tecnologia. A distribuição por tempo de casa sugere que a organização alvo atualmente enfrenta perda de seus colaboradores de maneira mais forte em torno dos 18 meses de vínculo. Estratificando-se a amostra por tempo de casa, com intervalos de seis meses cumulativos, observa-se que $60,86 \%$ estão no seu primeiro ano na organização. Este percentual desce para 15,2\% para aqueles que estão entre um ano e 18 meses. Entre mais de 18 meses e dois anos, este percentual desce para 4,3\%. Podese inferir que uma razão provável seria a conclusão do curso universitário, o que abre maior leque de opções de emprego no mercado aos concludentes.

\section{Resultados e Discussão}

A Tabela 1 apresenta o perfil da amostra em relação ao comprometimento com a organização e com a obtenção do nível 2 do CMM, através da aplicação dos instrumentos. Pode-se observar médias altas em ambos comprometimentos. No entanto, o valor do mínimo em relação ao objetivo espelha um nível de variação menor, comprovado pelo desvio padrão, apontando para uma uniformidade em torno deste objetivo organizacional. Esta é uma indicação que os indivíduos podem perceber o objetivo organizacional focado (atingir o nível 2 de maturidade no modelo CMM) como algo que é positivo para eles individualmente. Vale ressaltar o caráter motivacional dos objetivos, estudado por Locke e Latham (1984). A organização alvo trabalhou a disseminação deste objetivo, através de práticas de gestão do comprometimento, como eventos, treinamentos, divulgação dos benefícios, o que parece ter conseguido envolver os empregados, fortalecendo seu comprometimento com o objetivo buscado.

Tabela 1 - Descrição dos Resultados Obtidos em Relação ao Comprometimento

\begin{tabular}{|l|c|c|c|c|c|}
\hline & $\mathrm{N}$ & Mínimo & Máximo & Média & Desvio Padrão \\
\hline Comp. Organização (Afetivo Meyer-Allen) & 110 & 2,67 & 7,00 & 5,3030 &, 9190 \\
\hline Comp. C/ objetivo (CMM nível 2) & 110 & 4,60 & 7,00 & 6,3236 &, 6502 \\
\hline
\end{tabular}

Embora os estudos sobre comprometimento apontem suas correlações com variáveis demográficas, conforme comprova a clássica meta análise de Mathieu e Zajac 


\section{Simpósio Brasileiro de Qualidade de Software}

(1990), o comprometimento com a organização, bem como o comprometimento com a obtenção do nível 2 do CMM não apresentaram correlações significativas com variáveis demográficas (faixa estaria, escolaridade, renda individual, quantidade de dependentes). A Tabela 2 apresenta as médias de comprometimento por variáveis demográficas. Meyer e Allen (1993) sugerem que trabalhadores com maior idade tornam-se mais comprometidos com a organização, por razões diversas como, por exemplo, ter conseguido posições de destaque. Meyer et al. (2002) complementam que idade correlaciona-se de maneira fraca e positiva com comprometimento, ressaltando que esta fragilidade é comum no tocante às correlações com variáveis demográficas.

A única observação que foi possível identificar nesta amostra, no tocante a idade, foi uma diminuição do comprometimento com a organização na faixa dos 26 a 30 anos de idade, o que pode remeter à época de consolidação da posição na empresa aliada a uma possível mudança de unidade ou não ter conseguido uma posição de destaque. Em relação à escolaridade, os indivíduos de baixa escolaridade apresentaram um nível de comprometimento com a organização bem abaixo dos demais, o que não ocorreu com o comprometimento com a consecução do objetivo. Vale salientar que o percentual destes na amostra é muito baixo, o que invalida um quadro mais conclusivo.

Em relação ao nível de escolaridade, MOWDAY et al. (1982) sugerem uma tendência de correlação negativa com comprometimento com a organização, resultando do fato que indivíduos mais educados possuem mais expectativas em relação à organização, bem como mais opções de emprego. Isto não foi observado nesta pesquisa. Ocorreu justamente o contrário. Aqueles que apresentam maior nível de escolaridade (pós-graduados) são justamente os que apresentam maiores níveis de comprometimento com os dois focos. As mulheres tendem a serem mais comprometidas do que os homens (FINK, 1992; MATHIEU e ZAJAC, 1990), o que foi observado neste estudo em relação ao comprometimento com o objetivo.

Estado civil é uma variável que tem apresentado relação positiva, mas baixa, com comprometimento. Pessoas casadas apresentam a tendência de apresentarem maiores níveis de comprometimento, o que foi observado neste estudo de maneira discreta, com médias mais altas para os indivíduos que não são solteiros (MATHIEU e ZAJAC, 1990). Os resultados apresentam níveis de comprometimentos ligeiramente mais altos para indivíduos com mais de 2 dependentes. Indivíduos na faixa de maior renda individual também apresentaram índices mais altos. Já em relação à renda familiar, observa-se que a maior média de comprometimento com o objetivo está na faixa de renda familiar mais baixa.

Tabela 2 - Médias de Comprometimento por Variáveis Demográficas

\begin{tabular}{|l|c|r|r|}
\hline N=110 & & Comp. c/ a Organização & $\begin{array}{l}\text { Comp. Com o Objetivo CMM } \\
\text { n.2 }\end{array}$ \\
\hline \multicolumn{5}{|r|}{ FAIXA ETÁRIA } \\
\hline Até 25 Anos & 81 & 5,3560 & 6,3259 \\
\hline De 26 A 30 Anos & 19 & 4,9035 & 6,2737 \\
\hline De 31 A 35 Anos & 13 & 5,7333 & 6,2000 \\
\hline Acima De 36 Anos & 9 & 5,5000 & 6,5500 \\
\hline ESCOLARIDADE & & 4,4167 & 6,1000 \\
\hline $2^{\circ}$ Grau Incompleto & 2 & 5,2935 & 6,3343 \\
\hline Superior Incompleto & 67 & 5,2798 & 6,1429 \\
\hline Superior Completo & 28 &
\end{tabular}




\section{Simpósio Brasileiro de Qualidade de Software}

\begin{tabular}{|c|c|c|c|}
\hline Pós-Graduado & 13 & 5,5385 & 6,6923 \\
\hline \multicolumn{4}{|l|}{$\operatorname{SEXO}(\mathrm{N}=109)$} \\
\hline Masculino & 90 & 5,3508 & 6,2489 \\
\hline Feminino & 19 & 5,2241 & 6,6421 \\
\hline \multicolumn{4}{|l|}{ RENDA INDIVIDUAL } \\
\hline Até 4 SM & 70 & 5,2310 & 6,2857 \\
\hline De 5 até $8 \mathrm{SM}$ & 26 & 5,3910 & 6,2923 \\
\hline De 9 até $12 \mathrm{SM}$ & 7 & 5,3571 & 6,3714 \\
\hline Acima de $13 \mathrm{SM}$ & 7 & 5,6426 & 6,7714 \\
\hline \multicolumn{4}{|l|}{ RENDA FAMILIAR } \\
\hline Até $5 \mathrm{SM}$ & 8 & 5,4167 & 6,7000 \\
\hline De 6 até $10 \mathrm{SM}$ & 25 & 5,2133 & 6,1520 \\
\hline De 11 até $15 \mathrm{SM}$ & 26 & 5,2500 & 6,3423 \\
\hline De 16 até $20 \mathrm{SM}$ & 19 & 5,5702 & 6,3684 \\
\hline De 21 até $25 \mathrm{SM}$ & 5 & 5,9667 & 6,5600 \\
\hline Acima de $25 \mathrm{SM}$ & 27 & 5,0926 & 6,2296 \\
\hline \multicolumn{4}{|l|}{ ESTADO CIVIL } \\
\hline Solteiro & 91 & 5,2784 & 6,3077 \\
\hline Casado & 16 & 5,4063 & 6,4000 \\
\hline Outros & 3 & 5,5000 & 6,4000 \\
\hline \multicolumn{4}{|c|}{ QUANTIDADE DE DEPENDENTES } \\
\hline Nenhum & 86 & 5,2519 & 6,3140 \\
\hline $\mathrm{Um}$ & 7 & 5,5714 & 6,2571 \\
\hline Dois & 9 & 5,2778 & 6,2222 \\
\hline Acima de Dois & 8 & 5,6428 & 6,6000 \\
\hline
\end{tabular}

A Tabela 3, a seguir, apresenta as médias de comprometimento por variáveis funcionais. No tocante às variáveis funcionais (tempo de casa, posição ocupada e nível hierárquico), foi encontrada correlação altamente positiva de 0,526 , significativa no nível 0,01 , entre nível hierárquico e tempo de casa, o que indica que a organização tende a favorecer "a prata da casa" na ocupação dos postos mais altos. Wright e Bonnet (2002) apontam que o tempo de casa possui efeito moderador sobre o comprometimento com a organização. Para a amostra analisada, há uma tendência contrária, sendo possível observar o crescimento das médias do comprometimento com a organização. Não foi identificada relação relevante entre comprometimento com o objetivo e tempo de casa.

Em relação à posição ocupada, destaca-se que os indivíduos em funções de apoio ao processo de software, como testadores, inspetores de qualidade, e técnicos de gerência de configuração, apresentam os menores níveis de comprometimento com a organização, o que não lhes afeta o comprometimento com o objetivo, que é mais alto do que o nível apresentado por desenvolvedores e líderes de equipe. Os gerentes e coordenadores de projeto apresentam os níveis mais altos de comprometimento nos dois focos, indicando que fazem parte do padrão de duplo compromisso, que tem é característica de indivíduos altamente performáticos (Bastos e Costa, 2000).

Nível hierárquico apresenta correlação positiva de 0,196, significativa na ordem de 0,05, com comprometimento organizacional. Embora não tenha sido identificada correlação com comprometimento com o objetivo, pode-se verificar uma tendência crescente deste comprometimento, à medida que o nível hierárquico sobe, atestada através das médias obtidas. 
Tabela 3 - Médias de Comprometimento por Variáveis Funcionais

\begin{tabular}{|c|c|c|c|}
\hline $\mathrm{N}=\mathbf{1 1 0}$ & & Comp. c/ a Organização & Comp. Com o Objetivo (CMM n.2) \\
\hline \multicolumn{4}{|l|}{ TEMPO DE CASA } \\
\hline De 0 até 6 meses & 27 & 5,0494 & 6,2444 \\
\hline Mais de 6 até 12 meses & 30 & 5,1000 & 6,1733 \\
\hline Mais de 12 até 18 meses & 15 & 5,4111 & 6,3867 \\
\hline Mais de 18 até 24 meses & 4 & 5,6667 & 6,4000 \\
\hline Mais de 24 até 30 meses & 4 & 5,7500 & 6,1500 \\
\hline Mais de 30 meses & 12 & 5,9028 & 6,5833 \\
\hline \multicolumn{4}{|l|}{ POSIÇÃO OCUPADA } \\
\hline Gerente/Coordenador & 12 & 5,7639 & 6,7167 \\
\hline Líder de Equipe & 21 & 5,4127 & 6,2952 \\
\hline Desenvolvedor & 66 & 5,2500 & 6,2576 \\
\hline Apoio & 11 & 4,9091 & 6,3455 \\
\hline \multicolumn{4}{|l|}{ NÍVEL HIERÁRQUICO } \\
\hline $\begin{array}{r}\text { Estratégico } \\
\end{array}$ & 12 & 5,7639 & 6,7167 \\
\hline Tático & 21 & 5,4127 & 6,2952 \\
\hline Operacional & 77 & 5,2013 & 6,2701 \\
\hline
\end{tabular}

Para determinar os padrões de comprometimento, foram estabelecidos o primeiro e o terceiro quartis, que foram utilizados como centróides iniciais para a extração dos clusters, que são os grupos com indivíduos com níveis similares de comprometimento com a organização e com o objetivo. Os Clusters 1,2,3 e 4 representam respectivamente Duplo compromisso, Unilateral Organização, Unilateral Objetivo e Duplo Descompromisso. A distribuição dos casos por padrões de comprometimento revelou como padrão mais freqüente o duplo compromisso com $43,6 \%$, seguido pelo comprometimentos unilaterais, ambos com 25,4\%, e duplo descompromisso com $5,6 \%$. As diferenças entre os grupos relativas às medidas de comprometimento foram avaliadas através de análise de variância. Estas diferenças se mostraram significativas para o comprometimento organizacional $(\mathrm{F}=114,873, \mathrm{p}<.000)$ e para o comprometimento com o objetivo $(\mathrm{F}=111,342, \mathrm{p}<.000)$, demonstrando que o agrupamento permite diferenciar indivíduos com níveis distintos de comprometimento.

Algumas diferenças emergem da análise da composição dos grupos. Em relação à faixa etária, pode-se observar que $50 \%$ dos indivíduos que apresentam duplo descompromisso possuem entre 26 a 30 anos de idade. Quanto à organização variável sexo, percebe-se que, proporcionalmente, existem proporcionalmente menos homens nos clusters duplo compromisso e unilateral com a organização do que mulheres, apontando para um maior comprometimento com a organização por parte das mulheres. No tocante ao nível de renda individual, observa-se que 33,3\% dos duplo descompromissados estão na faixa de 9 a 12 salários mínimos. Já a renda familiar apresenta 66,7\% deste grupo na faixa de 6 a 10 salários mínimos. Não foram encontradas relações conclusivas em relação ao estado civil. Já em relação à quantidade de dependentes, pode-se observar a ausência de indivíduos com mais de dois dependentes no cluster Unilateral Organização.

Em relação às variáveis funcionais, é digno de nota que: $80 \%$ dos duplo descompromissados tem até 12 meses de tempo de casa, 66,7\% são desenvolvedores e $83,3 \%$ estão no nível hierárquico operacional. 
Tabela 4 - Caracterização dos padrões de comprometimento segundo variáveis demográficas e funcionais dos seus integrantes

\begin{tabular}{|c|c|c|c|c|c|}
\hline & $\begin{array}{c}\text { Amostra Global } \\
(\%) \\
\end{array}$ & \begin{tabular}{|c|} 
Duplo \\
Compromisso \\
$(\%)$ \\
\end{tabular} & $\begin{array}{c}\text { Unilateral } \\
\text { Organiz. } \\
(\%)\end{array}$ & $\begin{array}{c}\text { Unilateral } \\
\text { Objetivo } \\
(\%)\end{array}$ & $\begin{array}{c}\text { Duplo } \\
\text { Descompromisso } \\
(\%) \\
\end{array}$ \\
\hline \multicolumn{6}{|l|}{ Faixa Etária } \\
\hline Até 25 anos & 73,6 & 75,0 & 78,6 & 75,0 & 33,3 \\
\hline De 26 a 30 anos & 17,2 & 12,5 & 14,3 & 21,4 & 50,0 \\
\hline De 31 a 35 anos & 4,5 & 6,3 & 3,6 & 0,0 & 16,7 \\
\hline Acima de 36 anos & 4,5 & 6,32 & 3,6 & 3,6 & 0,00 \\
\hline \multicolumn{6}{|l|}{ Escolaridade } \\
\hline Médio Incompleto & 1,7 & 0,0 & 0,0 & 3,6 & 16,7 \\
\hline Superior Incompleto & 60,5 & 60,4 & 57,4 & 67,9 & 50,0 \\
\hline Superior Completo & 26,0 & 22,9 & 39,9 & 17,9 & 16,6 \\
\hline \begin{tabular}{|l|l} 
Pós-graduado \\
\end{tabular} & 11,8 & 16,7 & 3,6 & 10,7 & 16,7 \\
\hline \multicolumn{6}{|l|}{ Nível de Renda Individual } \\
\hline \begin{tabular}{|l|l|} 
Até 4 SM \\
\end{tabular} & 63,6 & 58,3 & 67,9 & 67,9 & 66,7 \\
\hline De 5 a 8 SM & 23,6 & 22,9 & 28,6 & 25,0 & 0,00 \\
\hline De 9 a $12 \mathrm{SM}$ & 6,3 & 8,3 & 0,0 & 3,6 & 33,3 \\
\hline De 13 a 16 SM & 2,7 & 2,1 & 3,6 & 3,6 & 0,00 \\
\hline De 17 a 20 SM & 0,9 & 2,1 & 0,00 & 0,00 & 0,00 \\
\hline Acima de $20 \mathrm{SM}$ & 2,7 & 6,3 & 0,00 & 0,00 & 0,00 \\
\hline \multicolumn{6}{|l|}{ Nível de Renda Familiar } \\
\hline Até $5 \mathrm{SM}$ & 7,3 & 8,3 & 0,0 & 14,3 & 0,00 \\
\hline De 6 a 10 SM & 22,7 & 22,9 & 21,4 & 14,3 & 66,67 \\
\hline De 11 a 15 SM & 23,6 & 20,8 & 28,6 & 28,6 & 0,00 \\
\hline De 16 a $20 \mathrm{SM}$ & 17,3 & 20,8 & 17,9 & 10,7 & 16,7 \\
\hline De 21 a 25 SM & 4,5 & 6,3 & 3,6 & 6,3 & 0,00 \\
\hline Acima de $25 \mathrm{SM}$ & 24,5 & 20,8 & 28,6 & 28,6 & 0,00 \\
\hline \multicolumn{6}{|l|}{ Estado Civil } \\
\hline Solteiro & 82,7 & 79,2 & 89,3 & 89,3 & 50,0 \\
\hline Casado & 14,5 & 16,7 & 10,7 & 10,7 & 33,3 \\
\hline Outros & 2,7 & 4,2 & 0,00 & 0,00 & 16,7 \\
\hline \multicolumn{6}{|l|}{ Sexo } \\
\hline Masculino & 82,5 & 75,0 & 58,06 & 85,7 & 81,8 \\
\hline Feminino & 17.5 & 25,0 & 41,94 & 14,3 & 17,2 \\
\hline \multicolumn{6}{|l|}{ Número de Dependentes } \\
\hline Nenhum & 78,2 & 70,8 & 82,1 & 92,9 & 50,0 \\
\hline Um & 6,4 & 8,3 & 7,1 & 0,0 & 16,7 \\
\hline Dois & 8,2 & 8,3 & 10,7 & 3,6 & 16,7 \\
\hline Três & 4,5 & 10,4 & 0,00 & 0,0 & 0,00 \\
\hline Quatro & 0,9 & 0,00 & 0,00 & 0,0 & 16,7 \\
\hline Cinco & 0,9 & 0,00 & 0,00 & 3,6 & 0,00 \\
\hline Seis & 0,9 & 2,1 & 0,00 & 0,00 & 0,00 \\
\hline \multicolumn{6}{|l|}{\begin{tabular}{|l|l|} 
Tempo de Casa \\
\end{tabular}} \\
\hline De 0 até 6 meses & 29,4 & 25,0 & 25,0 & 39,1 & 40,0 \\
\hline Mais de 6 até 12 meses & 32,6 & 22,5 & 50,0 & 30,4 & 40,0 \\
\hline Mais de 12 até 18 meses & 16,3 & 17,5 & 12,5 & 21,7 & 0,0 \\
\hline Mais de 18 até 24 meses & 4,3 & 5,0 & 4,2 & 4,3 & 0,0 \\
\hline Mais de 24 até 30 meses & 4,3 & 5,0 & 4,2 & 4,3 & 0,0 \\
\hline Mais de 30 meses & 13,0 & 25,8 & 4,2 & 0,0 & 20,0 \\
\hline
\end{tabular}




\section{Simpósio Brasileiro de Qualidade de Software}

\begin{tabular}{|l|r|r|r|r|r|}
\hline & Amostra Global & \multicolumn{1}{c|}{$\begin{array}{c}\text { Duplo } \\
\text { Compromisso } \\
(\mathbf{\%})\end{array}$} & $\begin{array}{c}\text { Unilateral } \\
\text { Organiz. } \\
(\mathbf{\%})\end{array}$ & $\begin{array}{c}\text { Unilateral } \\
\text { Objetivo } \\
(\mathbf{\%})\end{array}$ & $\begin{array}{c}\text { Duplo } \\
\text { Descompromisso } \\
(\%)\end{array}$ \\
\hline Posição & & & & & 16,7 \\
\hline Gerentes/Coordenadores & 10,9 & 20,8 & 0,0 & 3,6 & 0,0 \\
\hline Líderes de Equipe & 19,1 & 18,8 & 25,0 & 17,9 & 66,7 \\
\hline Desenvolvedores & 60,0 & 54,2 & 67,9 & 60,7 & 16,7 \\
\hline Apoio & 10,0 & 6,3 & 7,1 & 17,9 & 16,7 \\
\hline Nível Hierárquico & & & & & 0,0 \\
\hline Gerencial & 10,9 & 20,8 & 0,0 & 3,6 & 83,3 \\
\hline Tático & 19,1 & 18,8 & 25,0 & 17,9 & 78,6 \\
\hline Operacional & 70,0 & 60,4 & 75,0 & 7,0 & \\
\hline
\end{tabular}

No sentido de aprofundar o estudo das relações entre os comprometimentos abordados neste estudo, foi conduzida análise de regressão, utilizando o método stepwise. Constatou-se que o comprometimento com atingir o nível 2 do CMM é preditor do comprometimento organizacional na razão de 33,2\%. Este achado é condizente com Sull (2003), em sua afirmação de que comprometimentos representam a maneira como uma empresa assegura os recursos necessários para garantir sua sobrevivência, provendo maior clareza e foco aos empregados, ajudando-os a priorizar e coordenar suas ações. A Figura 2 ilustra este modelo. Ou seja, ao traçar o objetivo organizacional "atingir o nível 2 de maturidade", a organização potencializa maiores níveis de comprometimento por parte de seus colaboradores para si.

Sull (2003) acrescenta que comprometimentos são motivacionais, criando energia e paixões em tempos difíceis, inspirando os empregados a perseverar apesar de dificuldades e decepções. Eles definem indivíduos e organizações, mostrando quem são. Assim, a relação acima encontrada, que também coaduna com os achados de Locke e Latham (1984), aponta uma forma de construir comprometimentos, através do estabelecimento de objetivos, que sejam abraçados pelos indivíduos que formam a organização, como a busca por melhoria do processo de software.

Figura 2 - Relação entre Comprometimento com CMM e Comprometimento com a Organização

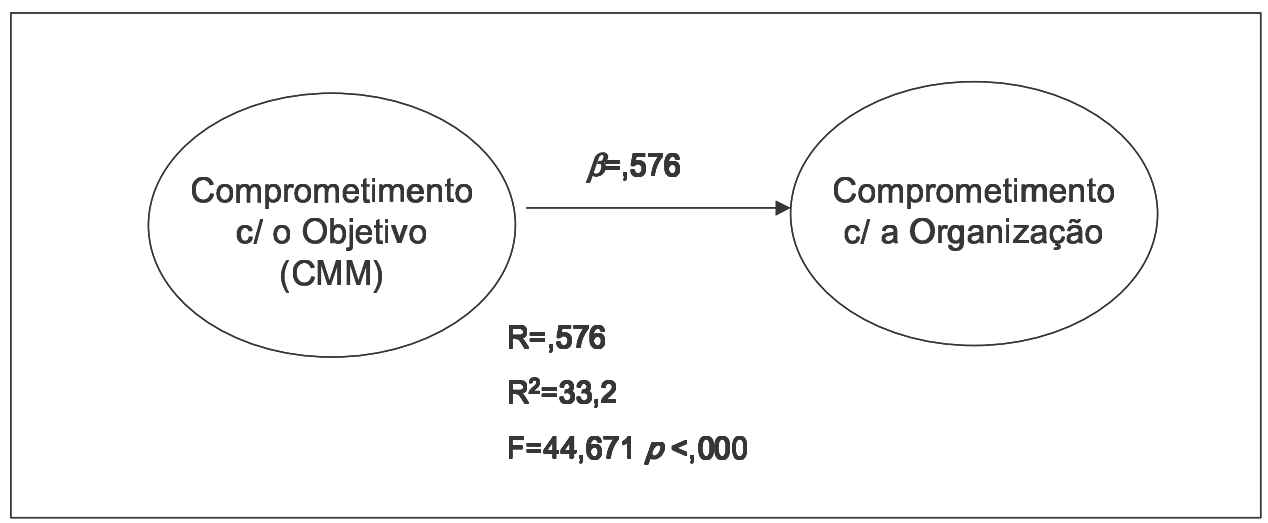




\section{Simpósio Brasileiro de Qualidade de Software}

\section{Conclusões}

Muitos pesquisadores têm apontado que alto desempenho no processo de software depende de forma decisiva do fator humano. Bandinelli et al. afirmam que uma perspectiva humana do processo enfatiza a cooperação social, onde a interação entre os componentes é fator chave. Assim, longe de terem uma influência periférica, questões humanas podem ser críticas para a eficácia do processo de software (ARBAUOI, 1999).

Comprometimentos, mais do que serem uma necessidade básica, podem ser um diferencial competitivo, se corretamente utilizados. Eles podem, por exemplo, convencer clientes a escolher fornecedores, a exemplo da adoção de um modelo como o CMM, bem como podem trazer benefícios internos para as organizações. Não são proclamações impessoais. Consistem em ações, decisões, promessas ou declarações de alta visibilidade, feitas por indivíduos e, portanto, mesmo quando referentes à uma organização, extremamente imbricados com as pessoas que os fazem. Para ter sucesso no panorama organizacional, eles devem que ser consistentes com a imagem de quem os faz, seus valores e ações passadas (SULL,2003). Portanto, conhecer comprometimentos, é conhecer as pessoas que os fazem. Neste contexto, este trabalho teve como objetivo analisar os comprometimentos com foco na organização e no objetivo atingir o nível 2 de maturidade no CMM, bem como suas relações com variáveis demográficas e funcionais.

As médias de comprometimento por variáveis demográficas e funcionais foram relatadas, permitindo identificar especificidades na amostra. Os padrões de comprometimento com os dois focos abordados foram identificados, que caracterizam os perfis dos profissionais que atuam em desenvolvimento de software, buscando encontrar especificidades deste tipo de atuação profissional. Determinou-se que o padrão de comprometimento que melhor caracteriza os profissionais da organização estudada é o duplo compromisso. Foi traçado o perfil demográfico e funcional do padrão duplo descompromisso nesta amostra.Observou-se uma correlação alta entre os dois focos, na ordem de 0,580. Através de análise de regressão, verificou-se que a adoção de um objetivo como implantar o CMM potencializa comprometimento organizacional. Desta forma, o comprometimento dos indivíduos com o CMM, e consequientemente com a organização, pode ser construído através da viabilização de oportunidades que permitam a construção de significados múltiplos para esta mudança, possibilitando aos indivíduos reconstituírem-se em meio a este processo.

Apesar de restringir-se a um estudo de caso, as conclusões deste estudo no tocante à relação entre os comprometimentos estão fortemente apoiadas pela literatura. Já no tocante às relações entre comprometimento e variáveis demográficas e funcionais, os resultados concordam com Scheible (2004). No entanto, para permitir uma generalização mais segura, a análise de outras amostras é indicada, pois ambos foram conduzidos na mesma organização.

Este estudo demonstra que mudanças organizacionais, como a implantação do modelo CMM, não são para as pessoas, ao contrário do que muitos administradores e teóricos sobre a gestão de mudança pensam, um "monstro aterrorizante" ao qual elas precisam resistir veementemente, a menos que consigam ser guiadas por um discurso que as ajude a racionalizar suas emoções. Isso foi comprovado pelo alto nível de 
comprometimento com este objetivo que traz em seu bojo uma mudança organizacional profunda. Alguns dos principais problemas relativos à gestão de mudanças organizacionais intencionais, como a implantação do CMM, identificados na literatura referem-se a dificuldades de: comunicar os objetivos da organização; tornar esses objetivos compreensíveis para as pessoas; e fazer com que as pessoas assimilem os objetivos e adotem as mudanças (SILVA e VERGARA, 2003). Uma das questões a serem investigadas no futuro são as práticas gerenciais que facilitam esta construção.

\section{Referências}

ABRAHAMSSON, P. The Role of Commitment in Software Process Improvement Process - Doctoral Thesis - University of Oulu, Oulu, 2002.

ARBAOUI S., LONCHAMP J. e MONTANGERO C. - The human dimension of the software process. In: Software Process: Principles, Methodology, and Technology. Derniame JC, Ali Kaba D \& Wastell D, ed: New York, p.165-200, 1999.

BASTOS, Antônio Virgílio B., O Conceito de Comprometimento - sua natureza e papel nas explicações do comportamento humano no trabalho, Cap.2, na Tese de Doutorado "Múltiplos comprometimentos no trabalho: a estrutura dos vínculos do trabalhador coma organização, a carreira e o sindicato", Universidade de Brasília, 1994.

Padrões de comprometimento com a profissão e a organização: O impacto de fatores pessoais e da natureza do trabalho. Revista de Administração (USP), São Paulo, v.35, n. 4, p. 48-60, 2000.

A Pesquisa sobre Comprometimento: um pouco da história e o percurso da investigação. Salvador, 2001. Material entregue na disciplina Indivíduos e Organizações do Mestrado Profissional em Administração, UFBA,turma 5.

BASTOS, Antonio Virgilio B., COSTA, Fabíola Marinho. Múltiplos comprometimentos no trabalho: articulando diferentes estratégias de pesquisa. In: XXIV ENCONTRO ANUAL DA ANPAD, 2000, Florianópolis.

BECKER H. S. Notes on the concept of commitment. American Journal of Sociology, v.66, n.1, p.32-40, 1960.

BENKHOFF, B. Disentangling organizational commitment The dangers of OCQ for research and policy. Personnel Review, v.26, n.1/2, p.114-131, 1997.

BROWN R. Organizational commitment: Clarifying the concept and simplifying the existing construct typology. Journal of Vocational Behavior, v.49, p.230-251, n.42, 1996.

DEMARCO, TOM e LISTER, TIMOTHY. Peopleware: Productive Projects and Teams. New York: Dorset House Publishing Co. 1999. 121 p.

FINK, Stephen. L. - High Commitment Workplaces, N. York Quorum Books, 1992.

HUMPHREY, Watts S. Managing the Software Process. SEI (Software Engineering Institute): Addison Wesley, 1989, cap.1 e 2.

The Commitment Ethic. In:__. Managing Technical

People. SEI (Software Engineering Institute): Addison Wesley, 1997, cap.2, p.13-20.

KIESLER, C.A. The Psychology of Commitment: Experiments Linking Behavior to Belief. 190p. Londres: Academic Press, 1971. 
MEDEIROS, C. A., Tese de Doutorado "COMPROMETIMENTO ORGANIZACIONAL: um estudo de suas relações com características organizacionais e desempenho nas empresas hoteleiras" - Universidade de São Paulo, 2003.

MCT, http://www.mct.gov.br/Temas/info/Dsi/qualidad/CMM.htm, Brasil, 2005.

MEYER, J.P., ALLEN, N.J. e SMITH, C.A. Commitment to organizations and occupations: Extension and test of a three-component conceptualization. Journal of Applied Psychology, v.78, n.4, p.538-551, 1993.

MEYER, JOHN P. e HERSCOVITCH, LYNNE Commitment in the workplace Toward a general model. Human Resource Management Review, v.11, n. 3, p.299-326, 2001.

MORROW, P.C. The Theory and Measurement of Work Commitment. Greenwich: JAI Press, 1993. 202 p.

MOWDAY, R.,Reflections on the Study and Relevance of Organizational Commitment. Human Resource Management Review, v.8, p.387-401, article n.4, 1998.

MOWDAY, R., PORTER, L., e STEERS, R.M. Employee-organization linkages: The psychology of commitment, absenteeism, and turnover. N. York: Academic Press, 1982.

PAUlK, M., WEBER, C., CURTIS, B., CHRISSIS, M. The Capability Maturity Model: Guidelines for Improving the Software Process, SEI (Software Engineering Institute): Addison Wesley, 1995, caps.1 e 2, p.3-28.

SABHERWAL, R., SEIN, M. K. e MARAKAS, G. M. Escalating Commitment to informational System Projects: Findings from Two Simulated Experiments. Information \& Management, v. 40, p. 781-798, 2003.

SABHERWAL, R., ELAM, J. Overcoming the Problems in Information Systems Development by Building and Sustaining Commitment. Accounting, Management \& Information Technology, v. 5, n.3/4,p. 283-309, 1995.

SALANCIK, Gerald R. Commitment and the Control of Organizational Behavior and Belief. In: New Directions in Oranizational Behavior. Chicago: St. Clair Press, 1977, cap. 1, p. 1-54.

SCHEIBLE, A., Dissertação de Mestrado "COMPROMETIMENTO NO TRABALHO: um estudo de caso de suas relações com desempenho e práticas de gestão" - Universidade Federal da Bahia, 2004.

SILVA, J. e VERGARA, S. Sentimentos, Subjetividade e Supostas Resistências à Mudança Organizacional. Revista de Administração de Empresas, v.42. n.3, 2003.

SULL, Donald. Managing by Commitments. Harvard Business Review On Point, n. 3957, Harvard Business School Publishing Corp., 2003.

WIENER, Y. Commitment in organizations: a normative view. Academy of Management Review, v 7,n 3, p 418-28, 1982.

WRIGHT, T., BONETT, D. The Moderating Effects of Employee Tenure on the Relation Between Commitment and Job Performance: A Meta-Analysis. Journal of Applied Psychology, v.87, n.6, p.1183-1190, 2002. 